\title{
The World Journal of Surgery Welcomes Dr. Tamara Fitzgerald to the Editorial Board
}

\author{
Julie Ann Sosa ${ }^{1}$
}

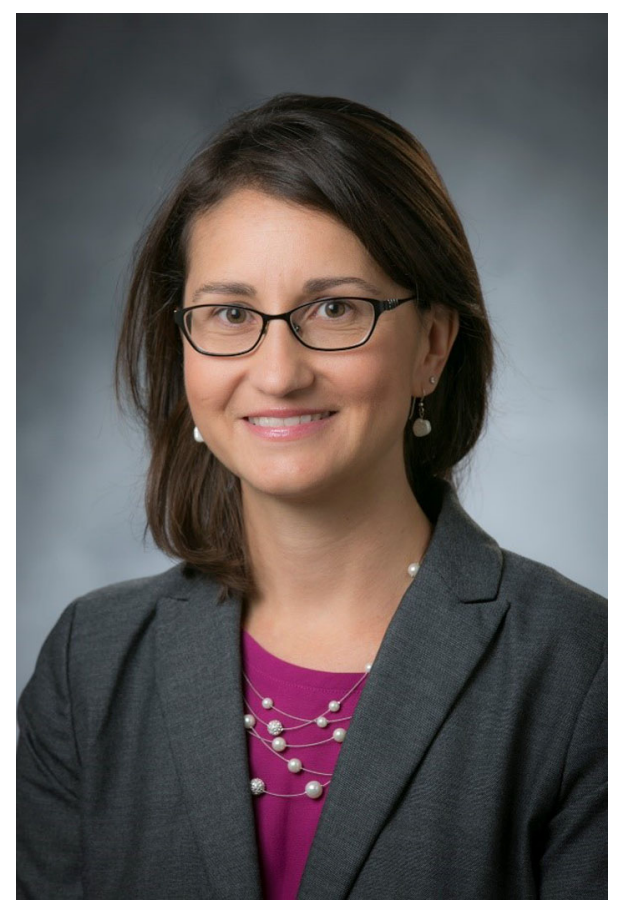

Julie Ann Sosa, MD, MA, FACS—Editor in Chief, World Journal of Surgery.
Tamara Fitzgerald is an Associate Professor in the Division of Pediatric Surgery at Duke University. She grew up in Northern California in the USA. She received her B.S. and Ph.D. in biomedical engineering and her M.D. from Boston University. She completed a general surgery residency and fellowship in pediatric surgery at Yale-New Haven Hospital. Her academic focus is global surgery. She participates in surgical capacity building, partnering with pediatric surgeons in sub-Saharan Africa to increase training and support for surgeons, thereby improving children's access to surgical care. Her research also focuses on developing cost-effective, quality biomedical devices for low- and middle-income countries. Dr. Fitzgerald is a mom to 2 teenagers, and in her free time she can be found at ballet class or kayaking down the waters of North Carolina with her family. Her website is scholars.duke.edu/ person/tamara.fitzgerald.

Publisher's Note Springer Nature remains neutral with regard to jurisdictional claims in published maps and institutional affiliations.

Julie Ann Sosa

julie.sosa@ucsf.edu

1 San Francisco, USA 